\title{
REACCIÓN DE 14 CULTIVARES DE PIMIENTO PAPRIKA (Capsicum annum L.) A DIFERENTES DENSIDADES DEL NEMATODO DEL NODULO meloidogyne incognita (KOFOID \& WHITE) CHITWOOD
}

\author{
REACTION OF BELL PEPPER 14 CULTIVARS (Capsicum annum L.) AT DIFFERENT \\ DENSITIES NODULE NEMATODE meloidogyne incognita (KOFOID \& WHITE) \\ CHITWOOD
}

${ }^{1}$ Carlos Cáceres Cubas y ${ }^{2}$ Angel Alfonso Palomo Herrera

\begin{abstract}
Resumen
Catorce cultivares de pimiento para páprika (Capsicum annuum L.) fueron evaluados para determinar su nivel de resistencia al nematodo del nódulo, Meloidogyne incognita, a nivel de invernadero. Cada uno de los cultivares fue inoculado con $0,10,100,250,500$ y 1000 huevos/100cc de suelo; para posteriormente ser evaluadas 100 días después de la inoculación. El efecto en el rendimiento se determinó comparando los cultivares inoculados con los no-inoculados, considerándose la variable de peso seco de la parte aérea. Con respecto a las variables nematológicas, se consideraron los índices de nodulación, el número de huevos/gramo de raíz fresca y la tasa de reproducción del nematodo.

Los cultivares AR-37100, Jaranda y Tietar mostraron altos niveles de resistencia, mientras que los cultivares Belrubí, Papri Queen, Papri Ace, Papri King, Sonora y PS 9794 mostraron ser tolerantes al ataque del nematodo. Los cultivares Real, Monarca, Híbrida, Norteño y Negral, mostraron ser susceptibles al ataque de Meloidogyne incognita.
\end{abstract}

Palabras clave: Capsicum annuum L., pimiento para páprika, Meloidogyne incognita, resistencia.

\begin{abstract}
Fourteen Pepper cultivars (Capsicum annuum L.) were tested for resistance to the root-knot nematode, Meloidogyne incognita under greenhouse conditions. Each cultivar was inoculated with 0, 10, 100, 250, 500 y 1000 eggs/100cc soil and subsequently, evaluated 100 days after inoculation. Yield responses were determined comparing the inoculated cultivars with the non-inoculated ones, considering the total dry weight of fruits and leaves. With respect to the nematologic variables; the ones considered were: the nodulation index, the number of eggs/gram of fresh root and the nematode reproduction rate. The cultivars AR-37100, Jaranda and Tietar showed high levels of resistance, while the cultivars Belrubí, Papri Queen, Papri Ace, Papri King, Sonora y PS9794 showed to be tolerant to the root-knot nematode infestation. The cultivars Real, Monarca, Híbrida, Norteño and Negral, showed to be susceptible to Meloidogyne incognita.
\end{abstract}

Key words: Capsicum annuum L., páprika pepper, Meloidogyne incognita, resistance.

\section{Introducción}

El pimiento páprika (Capsicum annuum), es el segundo producto de agroexportación hortícola de país. Las áreas sembradas con este cultivo han crecido de manera considerables en los últimos, y es cultivado principalmente en los valles de la costa peruana. El Perú es uno de los principales productores de pimiento páprika a nivel mundial y aporta cerca del $40 \%$ de la demanda mundial (2).

El nematodo del nódulo, Meloidogyne incógnita, es uno

\footnotetext{
${ }^{1}$ Ingeniero Agrónomo. Lima -Perú, E-mail: ccacerescubas@gmail.com

${ }^{2}$ Facultad de Agronomía - UNALM, Lima, Perú. E-mail: fonz@lamolina.edu.pe
} 
de los patógenos más importantes del Pimiento Páprika a nivel nacional. Los daños que causan a este cultivo bajo condiciones de monocultivos o en rotación con hospedantes favorables, pueden alcanzar niveles críticos que resulten en pérdidas sustanciales. Las principales medidas para hacer frente a este patógeno son las aplicaciones de nematicidas, la rotación de cultivos y el uso de prácticas agronómicas, tales como la incorporación de enmiendas orgánicas. Otra alternativa que puede ser efectiva y económica, especialmente para el pequeño agricultor, es el uso de cultivares tolerantes o resistentes que aseguren buenos rendimientos en presencia del nematodo y disminuyen la frecuencia de la aplicación de nematicidas.

La presente investigación tiene como objetivo identificar el comportamiento de catorce cultivares de pimiento para Paprika (Capsicum annuum L.) para determinar su nivel de resistencia bajo diferentes densidades poblacionales de Meloidogyne incognita (Kofoid \& White) bajo condiciones de invernadero.

\section{Revisión Bibliográfica}

\section{El Cultivo del Pimiento (Capsicum annuum L.)}

El pimiento páprika es una especie de pimiento cuyo nombre científico es Capsicum annuum L. "Paprika" proviene de una palabra Húngara que significa Pimiento.

El fruto es muy apreciado por la industria como colorante y saborizante (1).

Es una planta anual, herbácea, sistema radicular pivotante provisto y reforzado de un número elevado de raíces adventicias, el tallo de crecimiento limitado y erecto, con un porte que en término medio puede variar entre $0.5-1.5 \mathrm{~m}$. Cuando la planta alcanza cierta edad los tallos se lignifican ligeramente. Las hojas son glabras (sin pelos), enteras, ovales o lanceoladas con un ápice muy pronunciado (acuminado) y un pecíolo largo o poco aparente.

En el Perú el cultivo de pimiento páprika, se produce en Arequipa, Ica, Lima, Trujillo, Chiclayo y Piura, en zonas donde las temperaturas estén entre 18 a $25^{\circ} \mathrm{C}$. Puesto que si están fuera de este rango se producen frutas de mala calidad y bajo rendimiento. Se prefiere que durante la madurez de los frutos las temperaturas sean uniformes alrededor de $25^{\circ} \mathrm{C}$ puesto que la intensidad del color está directamente relacionada con la temperatura.

La cosecha se realiza manualmente, cuando la planta presenta frutos sobrepasado ligeramente su maduración, de color rojo intenso. Ésta se inicia aproximadamente de 5to mes después de la siembra. El fruto debe estar flácido con la punta algo arrugada, lo cual nos permite un secado uniforme. Los frutos turgentes son propensos a pudriciones y demoran en el secado. El color del páprika va cambiando de tonalidad de un rojo intenso en el momento de la cosecha a un rojo "concho de vino" al momento del secado (1).

El periodo de cosecha se extiende entre 45 - 60 días. Los porcentajes de primera están alrededor de $95 \%$ del total de la cosecha. $(1,2)$

En cuanto a estadísticas de exportación, el Perú es el primer exportador de páprika en el mundo; en el 2004, el Perú exporto 29,000 TM ( $36 \%$ ) de la actual demanda mundial estimada en $80,000 \mathrm{TM}$, en su mayoría comercializadas a través de España que participa con el $55 \%$ del mercado mundial (2).

\section{El nematodo del nódulo (Meloidogyne incognita)}

El nemátodo del nudo de la raíz, Meloidogyne incognita, daña a las plantas al debilitar las puntas de la raíz y al inhibir su desarrollo o estimular una formación radical excesiva, pero principalmente al inducir la formación de hinchamiento de las raíces, lo que no solo privan a las plantas de nutrientes, sino también del agua. El nemátodo estimula el crecimiento celular, licuando parte de su contenido, el cual succiona a través de su estilete $(3,8)$.

Los síntomas en los órganos aéreos no son conspicuos, pueden ser similares a los que producen otras enfermedades radiculares o factores del medio ambiente que ocasionan estrés de la planta por falta de agua. Las plantas infectadas muestran un desarrollo deficiente y una mayor cantidad de hojas pequeñas, de color verde pálido o amarillento que tiende a marchitarse cuando el clima es cálido. La inflorescencia y los frutos no se forman o se atrofia. Los síntomas más característicos son los que aparecen sobre los

Órganos subterráneos de las plantas. Las raíces infectadas se hinchan en la zona de invasión y desarrollan las agallas típicas del nudo de la raíz, las cuales tienen un diámetro 2 o 3 veces mayor al de las raíces sanas.

Además de las alteraciones que ocasionan las agallas a la planta, con frecuencia los daños que sufren las plantas infectadas se acrecientan debido a ciertos hongos parásitos, los cuales atacan con facilidad a los tejidos de las raíces debilitadas, siendo Fusarium, Pythium y Rhizoctonia los que crecen y se reproducen con mayor rapidez en las agallas que en otras áreas de la raíz $(4,9)$.

Las principales medidas de control son las del tipo cultural, aplicaciones de materia orgánica a razón 25 a $30 \mathrm{TM} / \mathrm{Ha}$ que bajan la acción dañina en el cultivo favoreciendo el desarrollo de los enemigos naturales de los nematodos, además de la desinfección de los equipos de trabajo, y hacer adecuadas fertilizaciones, principalmente la fosforada.

Las medidas del tipo químico son muy empleadas, utilizando nematicidas como el Oxamil y el Carbofuran.

Información sobre resistencia en Capsicum es limitada. Se ha observado resistencia al nematodo del nudo de la raíz en la línea pungente de C. Annuum variedad "Carolina Hot" que mostró resistencia a Meloidogyne spp. Fery 
(Thies y Fery, 2000) selecciono "Carolina Cayenne" de la población de "Carolina Hot" por segregación, obteniendo muchos rasgos incluidos la resistencia a M. Incógnita. "Carolina Cayenne" es resistente a M. Incógnita raza 1, 2,3 y 4, y a M. arenaria raza 1 y 2 (6).

Hare (citado por Thies y Fery, 2000) identifico cuatro pimientos cultivados con una alta resistencia a la subespecie $M$. incógnita acrita dos de los cultivares son "SantankaxS" y "405Bmexico", estos son algo resistentes a $M$. incognita, $M$. javanica y $M$. arenaria, pero no son resistentes a M. hapla. Esta resistencia de "SantankaxS" y "405Bmexico" es condicionado por un gen dominante el cual designó como gen N (5).

\section{Materiales y Métodos}

El experimento se llevó a cabo en las instalaciones del laboratorio de nematología "M. Oostenbrink "y en el Invernadero de nematología de la Universidad Nacional Agraria la Molina.

\section{Materiales.}

Cultivares de paprika (Tabla 1).

Inóculo de Meloidogyne.

Centrifuga.

Tamices.

Bolsas de $1 \mathrm{Kg}$.

Suelo estéril.

Tabla 1. Lista de los cultivares comerciales de Pimiento Páprika utilizados en el experimento.

\begin{tabular}{cc}
\hline Cultivares & Empresa Semillera \\
\hline AR 37100 & Ramiro Arnedo (España) \\
Belrubi & Ramiro Arnedo (España) \\
Jaranda & Ramiro Arnedo (España) \\
Tietar & Ramiro Arnedo (España) \\
Negral & Ramiro Arnedo (España) \\
PS 9794 & Seminis (EEUU) \\
Papri King & Seminis (EEUU) \\
Papri Queen & Seminis (EEUU) \\
Sonora & Seminis (EEUU) \\
Papri Ace & Seminis (EEUU) \\
Real & Seed export \\
Monarca & Seed export \\
Norteño & Seed export \\
Hibrido & Seed export \\
\hline
\end{tabular}

\section{Metodología}

La obtención del inóculo se obtuvo de raíces noduladas por Meloidogyne incógnita infectando plantas de tomate, se procedió a extraer los huevos de M. incógnita por el método del hipoclorito de sodio con una concentración de $0.5 \%(6)$.

La instalación del experimento:
1. A los 45 días del sembrado de las semillas de páprika se trasplantarón a bolsas conteniendo 1000 gramos de suelo estéril.

2. Quince días después del trasplante se inocularón huevos y juveniles 2 (J2) de Meloidogyne incognita a las densidades de $0,10,100,250,500$ y 1000 individuos por $100 \mathrm{cc}$ de suelo.

3. las evaluaciones se realizaron 100 días después de la inoculación.

Parámetros evaluados

1. Peso seco parte aérea $(\mathrm{g})$.

2. Peso fresco de raíz (g).

3. Tasa de reproducción del nematodo.

4. Numero de huevos de Meloidogyne/gramo de raíz..

5.

\section{Diseño Experimental}

El diseño experimental usado fue un diseño completo al azar (DCA) con 4 repeticiones, y los datos fueron analizados con SAS 6.08.

Tabla 2. Densidades poblacionales inoculadas en Reacción de 14 cultivares de pimiento paprika (Capsicum annuum l.) a diferentes densidades poblacionales del nematodo del nódulo Meloidogyne incognita (Kofoid \& White) Chitwood.

\begin{tabular}{lllllll}
\hline \multicolumn{5}{c}{ Tratamientos $\left(\mathrm{N}^{\circ}\right.$ de Huevos $/ 100$ cc de suelo $)$} \\
\hline Cultivares & T1 & T2 & T3 & T4 & T5 & T6 \\
\hline AR-37100 & 0 & 10 & 100 & 250 & 500 & 1000 \\
Jaranda & 0 & 10 & 100 & 250 & 500 & 1000 \\
Tietar & 0 & 10 & 100 & 250 & 500 & 1000 \\
Belrubi & 0 & 10 & 100 & 250 & 500 & 1000 \\
Papri-King & 0 & 10 & 100 & 250 & 500 & 1000 \\
Papri-Queen & 0 & 10 & 100 & 250 & 500 & 1000 \\
Sonora & 0 & 10 & 100 & 250 & 500 & 1000 \\
Papri-Ace & 0 & 10 & 100 & 250 & 500 & 1000 \\
PS 9794 & 0 & 10 & 100 & 250 & 500 & 1000 \\
Real & 0 & 10 & 100 & 250 & 500 & 1000 \\
Monarca & 0 & 10 & 100 & 250 & 500 & 1000 \\
Hibrida & 0 & 10 & 100 & 250 & 500 & 1000 \\
Norteño & 0 & 10 & 100 & 250 & 500 & 1000 \\
Negral & 0 & 10 & 100 & 250 & 500 & 1000 \\
\hline
\end{tabular}

\section{Resultado y Discusión}

Los resultados obtenidos en los catorce cultivares de pimiento para páprika (Capsicum annuum L.) ante diferentes densidades poblacionales de Meloidogyne incognita fueron agrupados según el comportamiento encontrado en los resultados, mostrando tener resistencia, otros tolerancia y/o susceptibilidad a $M$. incognita.

Los resultados de los parámetros de planta de peso seco parte aérea y peso fresco de raíz en el cultivar AR-37100, son los parámetros más constantes para analizar el efecto de las diferentes densidades de Meloidogyne incognita 
inoculadas. En el Tabla 4, donde se muestran los resultados del efecto en el crecimiento de la planta, se puede apreciar que el testigo no presenta diferencias significativas con la mayoría de las densidades de inoculación, excepto con la densidad de 1000 huevos/100cc de suelo, en donde se muestra un mayor peso de la parte aérea respecto al testigo. Asimismo, con respecto al peso fresco de raíces (Tabla 5) hay una ligera disminución en la mayoría de las densidades poblacionales inoculadas con respecto al testigo.

Seinhorst (1979), menciona que los nematodos ingresan en las raíces de plantas resistentes y dañan el tejido, resultando en una reducción del crecimiento de su masa aérea y/o radicular al igual que en plantas susceptibles. Asimismo, Khan et al (1991) mencionan que la penetración en la raíz en germoplasma resistente de juveniles 2 (J2) de $M$. incognita raza 1 y $M$. javanica se redujo significativamente a comparación de cultivares susceptibles, mientras que los $\mathrm{J} 2$ de ambas especies que lograron penetrar no se desarrollaron normalmente.

El desarrollo de J2 a J3, J4 a estadios adultos inmaduros fue retardado y algunos individuos llegaron a ser hembras adultas, las cuales eran pequeñas y de forma anormal.

Con respecto al efecto del cultivar AR-37100 sobre los parámetros de reproducción de $M$. incognita se obtiene que el número de huevos por gramo de raíz de $M$. incognita fue el más bajo de todos los cultivares en estudio, asimismo la tasa de reproducción $(\mathrm{Pf} / \mathrm{Pi})$ muestra que este cultivar es un hospedante eficiente de $M$. incognita a densidades de 10, 100 y 250 huevos/100cc de suelo, mientras que a densidades de 500 y 1000 huevos/100cc de suelo la planta se comporta como un hospedante no eficiente, ya que la tasa (Pf/Pi) es menor a 1.5.

En el Tabla 5, se observa que el mayor número de huevos por gramo de raíz es de 305 a una densidad de 1000 huevos/100cc de suelo.

Fery et al. (1998), mencionan que los cultivares de pimiento (C. annuum) tipo Bell "California Wonder" y "Charleston Belle" son resistentes a M. incognita y la producción de huevos por gramos de raíz que obtienen es de 946 y 1656 huevos por gramo de raíz, respectivamente. El cultivar AR-37100 muestra tener una menor producción de huevos que los cultivares mencionados anteriormente. Asimismo, se deduce de lo mencionado que AR-37100 es un cultivar con altos niveles de resistencia a $M$. incognita por cuanto pueden estar involucrados pocos o varios genes. Sin embargo, no se han encontrado referencias de los genes que posee este cultivar por lo que este trabajo podría ser el primer reporte sobre resistencia del cultivar AR-37100 al nematodo del nódulo Meloidogyne incognita.

Los cultivares Jaranda y Tietar muestran una resistencia moderada a densidades altas. El peso seco de la parte aérea (Tabla 3) para ambos cultivares no ha sido afectado significativamente en la densidad más alta (1000 huevos/100cc de suelo), sin embargo en las densidades poblacionales inoculadas de 250 y 500 huevos/100cc de suelo este parámetro si fue afectado significativamente. Es posible que durante el ensayo algunas de las repeticiones hayan sufrido deterioro radicular similar al ocasionado por algunos organismos que afectan la raíz alterando parcialmente los resultados.

El peso fresco de las raíces (Tabla 4) en ambos cultivares no muestran diferencias estadísticamente significativas entre las densidades inoculadas y el testigo. Sin embargo, el testigo presenta un mayor peso que las demás densidades. La disminución del peso de las raíces se vio más acentuada en el cultivar Tietar.

Con respecto a los parámetros de reproducción del nematodo en ambos cultivares vemos que ambos cultivares, junto con AR-37100 muestran las menores producciones de huevos por gramos de raíz que el resto de cultivares a diferentes densidades poblacionales en estudio. Asimismo, la tasa de reproducción ( $\mathrm{Pf} / \mathrm{Pi})$ (Tabla 6) muestra que ambos cultivares son hospedantes eficientes de $M$. incognita en las densidades de 10, 100 y 250 huevos/100cc de suelo, mientras que en densidades altas como 500 y 1000 huevos/100cc de suelo estos se comportan como hospedantes no eficientes del nematodo con Pf/Pi menor a 1.5. Los cultivares Tietar y Jaranda muestran una mayor tasa de reproducción y número de huevos por gramo de raíz que el cultivar AR-37100, estas diferencias posiblemente se deben a diferentes niveles de resistencia entre los cultivares. Algo similar ocurre en tomates resistentes a $M$. incognita ya que el nivel de resistencia que expresan está en función del genotipo receptor de gen $\mathrm{Mi}$, de la frecuencia de segregantes genéticos para el carácter de resistencia y de la constitución alélica del carácter; resultando en cultivares que expresan rangos intermedios de resistencia.

Los cultivares comerciales de pimiento para páprika que se siembran en el país son Papri Queen, Papri King y Sonora y muestran ser hospedantes eficientes de Meloidogyne incognita según los resultados obtenidos. En campo, los ataques más severos de este nematodo se observan en suelos arenosos, mientras que en suelos de valle el problema principal es Phytophthora capsici.

Los resultados de este trabajo son los primeros reportes que se realizan para estos cultivares inoculados con $M$. incognita bajo condiciones de invernadero.

El efecto de las diferentes densidades poblacionales inoculadas sobre los parámetros de peso seco del follaje y peso fresco de raíces sostienen que los cultivares muestran tolerancia al ataque de $M$. incognita. El peso seco del follaje no se ve afectado significativamente en los tres cultivares, aun cuando existe una ligera reducción del mismo.

El peso fresco de raíces del cultivar Papri Queen no se ve afectado, por el contrario, incrementó su peso, esto puede estar relacionado a un mayor nivel de tolerancia al ataque 
Tabla 3. Prueba de comparación de Duncan del peso fresco de raíces (g) de los 14 cultivares de páprika en las diferentes densidades poblacionales de Meloidogyne.

\begin{tabular}{|c|c|c|c|c|c|c|c|c|c|c|c|c|c|c|}
\hline & AR-37100 & Jaranda & Tietar & Belrubi & Papri King & Papri Queen & Sonora & Papri Ace & PS 9794 & Real & Monarca & Hibrida & Norteño & Negral \\
\hline $10 \mathrm{a}$ & $210 \mathrm{~B}$ & $309 \mathrm{C}$ & $316 \mathrm{C}$ & $3726 \mathrm{BC}$ & $4875 \mathrm{C}$ & $7733 \mathrm{C}$ & $1996 \mathrm{~B}$ & $1332 \mathrm{C}$ & $1104 \mathrm{D}$ & $1814 \mathrm{C}$ & $2588 \mathrm{C}$ & $1207 \mathrm{BC}$ & $502 \mathrm{~B}$ & $1131 \mathrm{~B}$ \\
\hline 100 & $586 \mathrm{~A}$ & $2290 \mathrm{~A}$ & $1118 \mathrm{~B}$ & 13104 B & $55780 \mathrm{~A}$ & $252070 \mathrm{~A}$ & $61121 \mathrm{~A}$ & $80005 \mathrm{~A}$ & $111752 \mathrm{~A}$ & $179139 \mathrm{~A}$ & $83464 \mathrm{~A}$ & $17716 \mathrm{~A}$ & $32278 \mathrm{~A}$ & $41897 \mathrm{~A}$ \\
\hline 250 & $673 \mathrm{~A}$ & $2290 \mathrm{AB}$ & $3408 \mathrm{~A}$ & $6821 \mathrm{~B}$ & 9394 BC & $22070 \mathrm{BC}$ & $15796 \mathrm{~A}$ & 11918 B & $25174 \mathrm{~B}$ & $8579 \mathrm{~B}$ & 9414 B & $6032 \mathrm{AB}$ & $19523 \mathrm{~A}$ & 29069 A \\
\hline 500 & 242 B & $720 \mathrm{BC}$ & $583 \mathrm{C}$ & $2251 \mathrm{C}$ & $14413 \mathrm{BC}$ & $121187 \mathrm{C}$ & $1066 \mathrm{~B}$ & 4944 B & $7863 \mathrm{C}$ & $1166 \mathrm{C}$ & $1094 \mathrm{C}$ & $722 \mathrm{C}$ & 2574 B & $732 \mathrm{~B}$ \\
\hline 1000 & $964 \mathrm{~A}$ & $1145 \mathrm{AB}$ & $1245 \mathrm{~B}$ & $62543 \mathrm{~A}$ & $16089 \mathrm{~B}$ & $102047 \mathrm{AB}$ & $107681 \mathrm{~A}$ & $10610 \mathrm{~B}$ & $65879 \mathrm{AB}$ & $78413 \mathrm{~A}$ & $123589 \mathrm{~A}$ & 3243 BC & $11136 \mathrm{~A}$ & $42757 \mathrm{~A}$ \\
\hline ANVA & $* *$ & $* *$ & $* *$ & $* *$ & $* *$ & $* *$ & $* *$ & $* *$ & $* *$ & $* *$ & $* *$ & $* *$ & $* *$ & $* *$ \\
\hline C.V & $4.27 \%$ & $7.32 \%$ & $3.89 \%$ & $5.15 \%$ & $5.88 \%$ & $10.21 \%$ & $8.31 \%$ & $7.10 \%$ & $5.53 \%$ & $4.07 \%$ & $6.02 \%$ & $10.71 \%$ & $9.09 \%$ & $4.96 \%$ \\
\hline
\end{tabular}

Tabla 4. Prueba de comparación de Duncan de la variable peso seco parte aérea (g) de los 14 cultivares de páprika en las diferentes densidades poblacionales de Meloidogyne.

\begin{tabular}{|c|c|c|c|c|c|c|c|c|c|c|c|c|c|c|}
\hline & AR-37100 & Jaranda & Tietar & Belrubi & Papri King & Papri Queen & Sonora & Papri Ace & PS 9794 & Real & Monarca & Hibrida & Norteño & Negral \\
\hline$\overline{0}$ & $8.65 \mathrm{a}$ & $6.93 \mathrm{a}$ & $7,98 \mathrm{ab}$ & $6.00 \mathrm{a}$ & $5.38 \mathrm{a}$ & $4.63 \mathrm{ab}$ & $6.40 \mathrm{a}$ & $6,78 \mathrm{a}$ & $6.00 \mathrm{a}$ & $7.70 \mathrm{a}$ & $7.00 \mathrm{a}$ & $6.13 \mathrm{a}$ & $4.75 \mathrm{a}$ & $5,60 \mathrm{a}$ \\
\hline 10 & $7.35 \mathrm{ab}$ & $7.15 \mathrm{a}$ & $5.93 \mathrm{~cd}$ & $5,38 \mathrm{a}$ & $5.68 \mathrm{a}$ & $3.23 \mathrm{~b}$ & $4.40 \mathrm{a}$ & $4,53 \mathrm{bc}$ & $4,50 \mathrm{a}$ & $5.33 \mathrm{bc}$ & $5.40 \mathrm{~b}$ & $4.50 \mathrm{~b}$ & $3.95 \mathrm{ab}$ & $3,87 \mathrm{~b}$ \\
\hline 100 & $8.73 \mathrm{a}$ & $7.45 \mathrm{a}$ & $8,48 \mathrm{a}$ & $6,10 \mathrm{a}$ & $4.78 \mathrm{ab}$ & $5.48 \mathrm{a}$ & $5.10 \mathrm{a}$ & $6,80 \mathrm{a}$ & $4,40 \mathrm{a}$ & $6.85 \mathrm{ab}$ & $7.53 \mathrm{a}$ & $4.80 \mathrm{ab}$ & $4.83 \mathrm{a}$ & $4,95 \mathrm{a}$ \\
\hline 250 & $5.83 \mathrm{~b}$ & $5.10 \mathrm{c}$ & $5,15 \mathrm{~d}$ & $4,33 \mathrm{a}$ & $3.23 \mathrm{bc}$ & $3.13 \mathrm{~b}$ & $3.83 \mathrm{a}$ & $3,35 \mathrm{c}$ & $3,25 \mathrm{a}$ & $4.15 \mathrm{c}$ & $3.70 \mathrm{~cd}$ & $2.53 \mathrm{c}$ & $2.73 \mathrm{c}$ & $2,25 \mathrm{c}$ \\
\hline 500 & $6.65 \mathrm{~b}$ & $5.33 \mathrm{bc}$ & $4,80 \mathrm{~d}$ & $4,63 \mathrm{a}$ & $3.03 \mathrm{c}$ & $3.00 \mathrm{~b}$ & $4.13 \mathrm{a}$ & $3,65 \mathrm{c}$ & $2,60 \mathrm{a}$ & $4.63 \mathrm{c}$ & $3.23 \mathrm{~d}$ & $2.95 \mathrm{c}$ & $2.48 \mathrm{c}$ & $2,02 \mathrm{c}$ \\
\hline 1000 & $9.23 \mathrm{a}$ & $6.33 \mathrm{ab}$ & $6,85 \mathrm{bc}$ & $5,20 \mathrm{a}$ & $4.48 \mathrm{ab}$ & $4.20 \mathrm{ab}$ & $4.73 \mathrm{a}$ & $6,08 \mathrm{ab}$ & $4.00 \mathrm{a}$ & $4.23 \mathrm{c}$ & $4.75 \mathrm{bc}$ & $2.83 \mathrm{c}$ & $3.13 \mathrm{bc}$ & $3,17 \mathrm{~b}$ \\
\hline ANVA & $* *$ & $* *$ & $* *$ & n.s & $* *$ & $* *$ & n.s & $* *$ & n.s & $* *$ & $* *$ & $* *$ & $* *$ & $* *$ \\
\hline C.V. & $6.98 \%$ & $5.41 \%$ & $5.76 \%$ & $9.41 \%$ & $9.76 \%$ & $12.81 \%$ & $9.83 \%$ & $9.69 \%$ & $15.64 \%$ & $8.47 \%$ & $7.43 \%$ & $8.99 \%$ & $6.49 \%$ & $6.03 \%$ \\
\hline
\end{tabular}

Valores en la misma columna seguidos por la misma letra no son estadisticamente significativos ( $\mathrm{p}=0.05)$, conforme a la prueba de Duncan.

a Tratamientos. Número de huevos de Meloidogyne/100cc de suelo.

ANVA: Análisis de variancia.

C.V: Coeficiente de variabilidad.

n.s No significativo

* Significativo

** Altamente significativo / Probabilidad 5\% 
REACCIÓN DE 14 CULTIVARES DE PIMIENTO PAPRIKA (Capsicum annum L.) A DIFERENTES DENSIDADES DEL NEMATODO

DEL NODULO meloidogyne incognita (KOFOID \& WHITE) CHITWOOD

Julio - Diciembre 2016

Tabla 5. Prueba de comparación de Duncan para el número de huevos/gramo de raíz en los 14 cultivares de páprika en las diferentes densidades poblacionales de Meloidogyne.

\begin{tabular}{|c|c|c|c|c|c|c|c|c|c|c|c|c|c|c|}
\hline & AR-37100 & Jaranda & Tietar & Belrubi & Papri King & Papri Queen & Sonora & Papri Ace & PS 9794 & Real & Monarca & Hibrida & Norteño & Negral \\
\hline$\overline{10 a}$ & $31 \mathrm{c}$ & $76 \mathrm{~b}$ & $78 \mathrm{c}$ & $1154 \mathrm{c}$ & $2082 \mathrm{c}$ & $2968 \mathrm{c}$ & $720 \mathrm{~b}$ & $472 \mathrm{c}$ & $479 \mathrm{~d}$ & $532 \mathrm{c}$ & $800 \mathrm{c}$ & 402 bc & $185 \mathrm{~d}$ & $547 \mathrm{~b}$ \\
\hline 100 & $104 \mathrm{~b}$ & $841 \mathrm{a}$ & $450 \mathrm{~b}$ & $7882 \mathrm{~b}$ & $26057 \mathrm{a}$ & $150027 \mathrm{a}$ & $40031 \mathrm{a}$ & $43588 \mathrm{a}$ & $100803 \mathrm{a}$ & $69445 \mathrm{a}$ & $37766 \mathrm{a}$ & $33782 \mathrm{a}$ & 88079 a & $34053 \mathrm{a}$ \\
\hline 250 & $187 \mathrm{a}$ & $756 \mathrm{a}$ & $1080 \mathrm{a}$ & $2114 b c$ & $1869 \mathrm{c}$ & $7531 \mathrm{bc}$ & $6398 \mathrm{a}$ & $6806 \mathrm{~b}$ & $18120 \mathrm{~b}$ & $3255 \mathrm{~b}$ & $3610 \mathrm{~b}$ & $24.65 \mathrm{~b}$ & $16829 \mathrm{~b}$ & $12389 \mathrm{a}$ \\
\hline 500 & $66 \mathrm{~b}$ & $130 \mathrm{~b}$ & $214 \mathrm{~b}$ & $1007 \mathrm{c}$ & $9160 \mathrm{~b}$ & $128466 \mathrm{bc}$ & $571 \mathrm{~b}$ & $2702 b$ & $6401 \mathrm{c}$ & $680 \mathrm{c}$ & $216 \mathrm{~d}$ & $242 \mathrm{c}$ & $1472 \mathrm{c}$ & $108 \mathrm{c}$ \\
\hline 1000 & $305 \mathrm{a}$ & $374 \mathrm{a}$ & $410 \mathrm{~b}$ & $28650 \mathrm{a}$ & $7183 \mathrm{~b}$ & $49191 \mathrm{ab}$ & $48754 \mathrm{a}$ & $3292 \mathrm{~b}$ & $32062 \mathrm{~b}$ & $32448 \mathrm{a}$ & $69597 \mathrm{a}$ & $4168 \mathrm{~b}$ & $11100 \mathrm{~b}$ & $29537 \mathrm{a}$ \\
\hline ANVA & $* *$ & $* *$ & $* *$ & $* *$ & $* *$ & $*$ & $* *$ & $* *$ & $* *$ & $* *$ & $* *$ & $* *$ & $* *$ & $* *$ \\
\hline C.V. & $9.01 \%$ & $15.89 \%$ & $8.80 \%$ & $9.47 \%$ & $8.11 \%$ & $16.39 \%$ & $12.22 \%$ & $10.99 \%$ & $7.03 \%$ & $7.64 \%$ & $7.64 \%$ & $20.12 \%$ & $8.64 \%$ & $14.79 \%$ \\
\hline
\end{tabular}

Tabla 6. Prueba de comparación de Duncan para la tasa de reproducción (Pf/Pi) en los 14 cultivares de páprika en las diferentes densidades poblacionales de Meloidogyne.

\begin{tabular}{|c|c|c|c|c|c|c|c|c|c|c|c|c|c|c|}
\hline & AR-37100 & Jaranda & Tietar & Belrubi & Papri King & Papri Queen & Sonora & Papri Ace & PS 9794 & Real & Monarca & Hibrida & Norteño & Negral \\
\hline$\overline{10 a}$ & $95 \mathrm{~A}$ & $100 \mathrm{~A}$ & $100 \mathrm{~A}$ & $625 \mathrm{~A}$ & $150 \mathrm{D}$ & $625 \mathrm{~A}$ & $100 \mathrm{~B}$ & $100 \mathrm{C}$ & $125 \mathrm{C}$ & $375 \mathrm{~A}$ & $500 \mathrm{C}$ & $400 \mathrm{~B}$ & $175 \mathrm{~B}$ & $100 \mathrm{~B}$ \\
\hline 100 & $110 \mathrm{~A}$ & $150 \mathrm{~A}$ & $125 \mathrm{~A}$ & $650 \mathrm{~A}$ & $800 \mathrm{BC}$ & $3025 \mathrm{~A}$ & $2075 \mathrm{~A}$ & $675 \mathrm{~B}$ & $1625 \mathrm{AB}$ & $2750 \mathrm{~A}$ & $3400 \mathrm{~A}$ & $825 \mathrm{~B}$ & $1450 \mathrm{~A}$ & $5375 \mathrm{~A}$ \\
\hline 250 & $95 \mathrm{~A}$ & $125 \mathrm{~A}$ & $75 \mathrm{~A}$ & $2075 \mathrm{~A}$ & $5325 \mathrm{~A}$ & $2150 \mathrm{~A}$ & $1225 \mathrm{~A}$ & $875 \mathrm{~B}$ & $3475 \mathrm{~A}$ & $800 \mathrm{~A}$ & $3150 \mathrm{AB}$ & $4750 \mathrm{~A}$ & $3325 \mathrm{~A}$ & $5250 \mathrm{~A}$ \\
\hline 500 & $85 \mathrm{~A}$ & $375 \mathrm{~A}$ & $150 \mathrm{~A}$ & $625 \mathrm{~A}$ & $650 \mathrm{CD}$ & $750 \mathrm{~A}$ & $575 \mathrm{~A}$ & $850 \mathrm{~B}$ & $550 \mathrm{~B}$ & $425 \mathrm{~A}$ & $900 \mathrm{BC}$ & $500 \mathrm{~B}$ & $1525 \mathrm{~A}$ & $675 \mathrm{~B}$ \\
\hline 1000 & $50 \mathrm{~A}$ & $175 \mathrm{~A}$ & $225 \mathrm{~A}$ & $300 \mathrm{~A}$ & $3375 \mathrm{AB}$ & $1575 \mathrm{~A}$ & $1275 \mathrm{~A}$ & $2125 \mathrm{~A}$ & $2075 \mathrm{~B}$ & $700 \mathrm{~A}$ & $750 \mathrm{C}$ & $200 \mathrm{~B}$ & $2200 \mathrm{~A}$ & $1700 \mathrm{~B}$ \\
\hline ANVA & n.s & n.s & n.s & n.s & $* *$ & n.s & $* *$ & $* *$ & $* *$ & n.s & $* *$ & $*$ & $* *$ & $* *$ \\
\hline C.V & $6.99 \%$ & $7.32 \%$ & $23.26 \%$ & $10.50 \%$ & $10.52 \%$ & $9.65 \%$ & $9.76 \%$ & $8.52 \%$ & $8.09 \%$ & $15.59 \%$ & $9.32 \%$ & $13.16 \%$ & $9.96 \%$ & $12.09 \%$ \\
\hline
\end{tabular}

Valores en la misma columna seguidos por la misma letra no son estadisticamente significativos ( $\mathrm{p}=0.05$ ), conforme a la prueba de Duncan.

a Tratamientos. Número de huevos de Meloidogyne/100cc de suelo.

ANVA: Análisis de variancia.

C.V: Coeficiente de variabilidad.

n.s No significativo. / Probabilidad 5\%

* Significativo

** Altamente significativo. 
del nematodo en comparación con los cultivares Papri King y Sonora los cuales si son afectados en el peso de las raíces, siendo Sonora el más afectado con una drástica disminución en el mismo. Se observó que el cultivar Papri Queen emitía mayor número de raíces que Papri King y Sonora, por lo que este mecanismo podría estar relacionado con algunos genes de resistencia presentes en el cultivar.

Con respecto al efecto de los cultivares sobre la reproducción del nematodo se observa que los tres cultivares son hospedantes eficientes ya que poseen tasas de reproducción mayores a 1.5. El número de huevos/ gramo de raíz es elevado en los tres cultivares; el cultivar Papri Queen debido a su mayor producción de masa radicular presenta una mayor cantidad de huevos y tasa de reproducción. Según la escala de evaluación propuesta por Dropkin modificada por Canto Sáenz estos cultivares serían tolerantes, sin embargo, los cultivares Papri Queen y Papri King presentan un mayor desarrollo radicular y aéreo a densidades altas, permitiendo una mejor respuesta frente al nematodo por lo que se les considera más resistentes que Sonora.

Los cultivares Papri Ace, Belrubí y PS-9794, están agrupados por presentar un comportamiento similar frente al ataque de Meloidogyne incognita. El peso seco de la parte aérea (Tabla 3) indica que estadísticamente no hay diferencias entre el testigo y las densidades poblacionales inoculadas aún cuando se presenta una ligera reducción del peso en estos tres cultivares. Con respecto al peso fresco de las raíces (Tabla 4) se observa la misma tendencia que el peso seco de la parte aérea.

En relación al efecto de los cultivares sobre la reproducción del nematodo se observa que el número de huevos por gramo de raíz en los cultivares Belrubí y Papri Ace es mucho menor que en el cultivar PS-9794; al analizar la tasa de reproducción ( $\mathrm{Pf} / \mathrm{Pi}$ ) en las diferentes densidades poblaciones inoculadas, los tres cultivares muestran ser hospedantes eficientes del nematodo.

Estos cultivares no vieron afectados de manera significativa su peso seco de la parte aérea a la densidad de inoculación más elevada (1000 huevos/100cc de suelo), por tanto son considerados tolerantes al ataque del nematodo.

Se observó que los cultivares Belrubí y Papri Ace muestran ser más tolerantes que el cultivar PS-9794 ya que ambos presentan una mayor producción de masa radicular al igual que Papri Queen y Papri King, mientras que el cultivar PS-9794 muestra un mayor deterioro de las raíces frente al ataque del nematodo a densidades altas.

Los cultivares Negral, Norteño, Hibrida, Real y Monarca han sido agrupados en función a su similar reacción a las diferentes densidades poblacionales inoculadas de Meloidogyne incognita. Los parámetros obtenidos de peso fresco de raíces confirman el efecto detrimental que causa este nematodo sobre estos cultivares. El efecto del nematodo se observa en todas las densidades de inoculación, sin embargo, a densidades de 500 y 1000 huevos, el peso de la biomasa aérea se ve muy afectado al igual que el peso de raíces debido a que la raíz colapsa en estas densidades.

Lindsey et al (1982) inocularon diferentes densidades poblaciones en 3 cultivares de pimiento (Capsicum annuиm) y encontró que la densidad mínima dañina en estos cultivares creciendo en suelo arenoso era de aproximadamente 0.8 a 1.2 huevos y J2/cc de suelo. Di Vito et al. (19) encontraron un límite de tolerancia en el cultivar "Yolo Wonder" de 2.2 huevos y J2/cc de suelo. Estos autores mencionan los bajos niveles poblaciones que afectan a Capsicum annuum.

Con respecto al efecto de los cultivares Negral, Norteño, Hibrida, Real y Monarca en la reproducción de $M$. incognita, se observa en la Tabla 6 que los 5 cultivares tienen una tasa de reproducción $(\mathrm{Pf} / \mathrm{Pi})$ mayor a 1.5 por lo que son considerados como hospedantes eficientes de $M$. incognita en las diferentes densidades poblaciones inoculadas. Sin embargo, se observa que la tasa de reproducción en la densidad de 500 huevos/100 cc de suelo baja en los 5 cultivares de manera considerable debido a que su sistema radicular está totalmente dañado por lo que se deduce que la tasa de reproducción (Pf/ $\mathrm{Pi}$ ) no es un buen parámetro para medir la eficiencia del hospedante ya que no toma en cuenta el sistema radicular de la planta. Esta tasa debe ir acompañada del número de huevos/gramo de raíz (Tabla 5) siendo esto más preciso ya que se refiere a una misma unidad de evaluación como es el peso de las raíces o desarrollo radicular de la planta.

El número de huevos por gramo de raíz (Tabla 5) en los 5 cultivares, muestra una alta producción de huevos debido a la susceptibilidad al nematodo. Sin embargo se observa que a la densidad de 10 huevos/100cc de suelo la cantidad de estos es baja en los cinco cultivares, posiblemente debido a la presencia de genes complementarios o menores que restringen el desarrollo satisfactorio del nematodo a densidades bajas.

\section{Conclusiones}

En las condiciones en que se llevó a cabo el experimento se puede concluir lo siguiente:

Los cultivares AR-37100, Jaranda y Tietar han mostrado tener un comportamiento de hospedantes no eficientes de Meloidogyne incognita en las densidades poblacionales de 500 y 1000 huevos/100cc de suelo.

Los cultivares AR-37100, Jaranda y Tietar se comportan como plantas resistentes a $M$. incognita en la densidad poblacional más alta (1000 huevos/100cc de suelo).

Los cultivares Belrubí, Papri Queen, Papri Ace, Papri King, Sonora y PS 9794 mostraron ser tolerantes al ataque de $\mathrm{M}$. incognita a la densidad poblacional de 1000 huevos/100cc de suelo, sin embargo los 3 primeros 
cultivares mostraron una mayor tolerancia.

Los cultivares Negral, Norteño, Hibrida, Real y Monarca mostraron ser hospedantes eficientes de Meloidogyne incognita en todas las densidades poblacionales inoculadas, asimismo se comportan como susceptibles al ataque del nematodo en todas las densidades poblacionales.

\section{Literatura citada.}

Cepeda, S. M. 1996. Nematología Agrícola. Editorial Trillas. Primera edición-México

Fery, R. L., P. Dukes, and J. A. Thies. 1998. "Carolina Wonder" and "Charleston Belle": Southern Root-knot Nematode Resistant Bell Peppers. Hortscience 33(5): 900-902.

Guía del cultivo del Páprika.JB Ingenieros. 2005. Lima - Perú.

Hussey, R., and K. R. Barker. 1973. A comparison of methods of collecting inocula of Meloidogyne spp. Including a new technique. Plant Dis. Reptr. 57:10251028

Khan, A. A. and Khan, M. W. 1991. Penetration and development of Meloidogyne incognita racel and Meloidogyne javanica in susceptible and resistant vegetables. Nematrópica 21:71-77.

Linsdey, D. L., and Clayshulte, M. S. 1982. Influence of initial population densities of Meloidogyne incognita on three chile cultivars. Journal of Nematology 14 : 353 357.

Luc, M; Sikora, R.A y Bridge, J. 1990. Plant Parasitic Nematodes in Subtropical and Tropical Agriculture. Internartional Institute Parasitology.

Palomo, A. 2004. Separatas de curso de fitonematologia. Departamento de Entomología y Fitopatología-UNALM.

Resumen del 1er Seminario Internacional del Capsicum. 2005. Trujillo-Perú.

Seinhorst, J. W. 1979. Nematodes and Plant Growth. In Root-Knot Nematodes (Meloidogyne species) Systematics, Biology and Control. Editors F. Lamberti and C.E. Taylor. Academic Press.

Taylor, A.L y Sasser, J. N. 1978. Biology, Identification and Control root-knot nematode (Meloidogyne spp) North Carolina State University Graphic.

Thies, J. A; Fery, R. L. 2000. Characterization of Resistance conferred by the $\mathrm{N}$ gene to Meloidogyne arenaria races 1 y 2, M. hapla, and M. javanica in two sets of isogenic lines of Capsicum annuum L. J. Amer. Hort.Sci. 125(1): 71-75.

Zeck, W. M. 1971. A Rating scheme for Field evaluation of root-knot nematode infestations. Pflanzenschutz Nachriten Bayer. 24: 144-144 